\title{
Optimization of Soil Hydraulic Model Parameters Using Synthetic Aperture Radar Data: An Integrated Multidisciplinary Approach
}

Pauwels, Valentijn; Balenzano, Anna; Satalino, Giuseppe; Skriver, Henning; Verhoest, Niko; Mattia, Francesco

Published in:

I E E E Transactions on Geoscience and Remote Sensing

Link to article, DOI:

10.1109/TGRS.2008.2007849

Publication date:

2009

Document Version

Publisher's PDF, also known as Version of record

Link back to DTU Orbit

Citation (APA):

Pauwels, V., Balenzano, A., Satalino, G., Skriver, H., Verhoest, N., \& Mattia, F. (2009). Optimization of Soil Hydraulic Model Parameters Using Synthetic Aperture Radar Data: An Integrated Multidisciplinary Approach. I E E E Transactions on Geoscience and Remote Sensing, 47(2), 455-467.

https://doi.org/10.1109/TGRS.2008.2007849

\section{General rights}

Copyright and moral rights for the publications made accessible in the public portal are retained by the authors and/or other copyright owners and it is a condition of accessing publications that users recognise and abide by the legal requirements associated with these rights.

- Users may download and print one copy of any publication from the public portal for the purpose of private study or research.

- You may not further distribute the material or use it for any profit-making activity or commercial gain

- You may freely distribute the URL identifying the publication in the public portal 


\title{
Optimization of Soil Hydraulic Model Parameters Using Synthetic Aperture Radar Data: An Integrated Multidisciplinary Approach
}

\author{
Valentijn R. N. Pauwels, Anna Balenzano, Giuseppe Satalino, Henning Skriver, \\ Niko E. C. Verhoest, and Francesco Mattia, Senior Member, IEEE
}

\begin{abstract}
It is widely recognized that Synthetic Aperture Radar (SAR) data are a very valuable source of information for the modeling of the interactions between the land surface and the atmosphere. During the last couple of decades, most of the research on the use of SAR data in hydrologic applications has been focused on the retrieval of land and biogeophysical parameters (e.g., soil moisture contents). One relatively unexplored issue consists of the optimization of soil hydraulic model parameters, such as, for example, hydraulic conductivity values, through remote sensing. This is due to the fact that no direct relationships between the remote-sensing observations, more specifically radar backscatter values, and the parameter values can be derived. However, land surface models can provide these relationships. The objective of this paper is to retrieve a number of soil physical model parameters through a combination of remote sensing and land surface modeling. Spatially distributed and multitemporal SAR-based soil moisture maps are the basis of the study. The surface soil moisture values are used in a parameter estimation procedure based on the Extended Kalman Filter equations. In fact, the land surface model is, thus, used to determine the relationship between the soil physical parameters and the remote-sensing data. An analysis is then performed, relating the retrieved soil parameters to the soil texture data available over the study area. The results of the study show that there is a potential to retrieve soil physical model parameters through a combination of land surface modeling and remote sensing.
\end{abstract}

Index Terms-Calibration, hydrology, parameter estimation, remote sensing, synthetic aperture radar (SAR).

\section{INTRODUCTION}

D URING THE last decades, the benefit of Synthetic Aperture Radar (SAR) data for the modeling of land surface processes has become widely accepted. The advantages of SAR data in this respect are twofold. On the one hand, a number of parameters needed for this type of modeling, for example,

Manuscript received December 28, 2007; revised April 30, 2008, July 9, 2008, and August 22, 2008. Current version published January 28, 2009. This work was supported in part by ESA under Grant 19558/06/NL/HE and in part by the Belgian Science Policy Office in the frame of the STEREO II programme under Project SR/00/100.

V. R. N. Pauwels and N. E. C. Verhoest are with the Laboratory of Hydrology and Water Management, Ghent University, 9000 Gent, Belgium.

A. Balenzano, G. Satalino, and F. Mattia are with Istituto di Studi sui Sistemi Intelligenti per l'Automazione, Consiglio Nazionale delle Ricerche, 70126 Bari, Italy.

H. Skriver is with the Technical University of Denmark, 2800 Lyngby, Denmark.

Color versions of one or more of the figures in this paper are available online at http://ieeexplore.ieee.org.

Digital Object Identifier 10.1109/TGRS.2008.2007849 land cover parameters, can be retrieved directly and used as model input. Examples of these parameters are land cover class, vegetation water content, and Leaf Area Indices (LAIs) [1][9]. On the other hand, remotely sensed observations of model outputs, more specifically surface soil moisture values, can be used to validate model results. Examples of studies that have focused on the retrieval of these variables can be found in [10]-[15]. Furthermore, these data can also be assimilated into the models, reducing the error in the model predictions. Since the pilot study of [16], a large number of studies have put hydrologic data assimilation in practice.

It is clear that up until now, most of the research on the use of SAR data in hydrologic applications has been focused on the retrieval of land cover and biogeophysical parameters, more specifically surface soil moisture values [17], [18]. One relatively unexplored issue is the retrieval of soil hydraulic parameters, such as, for example, hydraulic conductivity values, through remote sensing. This is due to the fact that no direct relationships between the remote-sensing observations, more specifically the radar backscatter values, and the parameter values can be derived. However, land surface models can provide these relationships. Attempts have already been performed to estimate saturated hydraulic conductivity values bypassing the use of a land-surface model, for example, through the extrapolation of a regression between changes in soil water content and the hydraulic conductivity [19], or the application of neural networks to multiple drying cycle brightness temperature data [20]. However, these studies suffer from the drawback of the requirement of in situ measurements of the remotely sensed soil parameter in order to establish the regression relationships. Furthermore, it is well known that soil parameter values are scale dependent, which is mainly caused by heterogeneity [21]. Hydraulic conductivity determined at a small scale is mainly caused by flow across heterogeneous soil particles, whereas at large scale, high-conductivity heterogeneities (preferential flow paths) will lead to large values for the hydraulic conductivity of the same soil. Many remote-sensing studies have already investigated the discrepancy between the scale of observation and the scale at which the parameter values are required (e.g., [22] and [23]). Reference [24] showed that soil moisture observations can be used to obtain the soil textural composition, but did not apply their methodology in order to retrieve spatially distributed parameter values. The objective of this paper is to develop a methodology to estimate spatially distributed soil 
hydraulic parameters, with two clear advantages. First, the parameters are retrieved at the spatial scale at which they are required. Second, the need to collect in situ soil moisture data or parameter values is bypassed. Accurate estimates of these parameters are important because they determine soil moisture profiles, which determine the partitioning of the precipitation into surface runoff and infiltration, and the net radiation into sensible, latent, and ground heat fluxes. In other words, these parameters are crucial for an accurate modeling of the processes occurring at the land surface.

The study has been performed as part of the AgriSAR 2006 campaign. The basis of the study is the integration of remotely sensed soil moisture values with the TOPMODEL [25]-based Land Atmosphere Transfer Scheme (TOPLATS) [26]. Volumetric soil moisture values are retrieved from multitemporal L-band SAR data at $\mathrm{HH}$ polarization. The moisture content refers to the top $10 \mathrm{~cm}$ of the soil, covering the thickness of the layer whose moisture content is estimated by the L-band data, unless extremely dry conditions are faced [1]. The algorithm applies to agricultural areas cultivated with winter wheat and inverts a surface scattering model, thus disregarding the small effect of wheat canopy on $\mathrm{HH}$ backscatter. This approximation stems from previous theoretical studies [27] and from a sensitivity analysis performed on L-band ESAR data acquired during the AgriSAR 2006 campaign [28]. The algorithm was developed for the possible use of data acquired by the Advanced Land Observing Satellite Phased Array-type L-band SAR system in default mode acquisitions [29]. A parameter estimation procedure is then applied to the soil parameter values, in order for TOPLATS to reproduce the remotely sensed soil moisture values. The spatial distribution of the obtained soil parameter values is then further examined, the remotely sensed values are compared to data from literature, and the potential to retrieve soil hydraulic parameters through a combination of remote sensing and land surface modeling is then assessed.

\section{Site Description}

The study has been performed in the framework of the AgriSAR 2006 campaign, for which the test site was located in Mecklenburg-Vorpommern in North-East Germany, approximately $150 \mathrm{~km}$ North of Berlin. Reference [30] give a detailed description of the campaign. Only a short summary will be given here. The test site has been the subject of a number of research projects, of which the most important is the Durable Environmental Multidisciplinary Monitoring Information Network (DEMMIN, ) project. The test site is based on a group of farms within a farming association covering approximately $250 \mathrm{~km}^{2}$. Field sizes are very large in this area, averaging between 2 and $2.5 \mathrm{~km}^{2}$. The main crops are winter wheat, winter barley, winter rape, corn, and sugar beet. The altitudinal range within the test site is approximately $50 \mathrm{~m}$. During the data acquisition period, which lasted from April to July 2006, several airborne radar and optical data acquisitions were performed. More specifically, the German Aerospace Center operated their Experimental SAR during 16 overpasses along two different tracks, whereas the Spanish Instituto Nacional de Técnica Aeroespacial carried out four flights, operating their
Airborne Hyperspectral Scanner and the Compact Airborne Spectrographic Imager (CASI-1500) for obtaining hyperspectral optical imagery [31]. Simultaneously, ground measurements, over a few selected fields, in terms of soil moisture contents and fresh and dry biomass, were carried out. In addition to these systematic measurements, three intensive campaigns of in situ measurements were carried out during the AgriSAR campaign. The first was held from April 19 to 21, the second from June 6 to 8 , and the third from July 4 to 6 . During these three campaigns, a large number of surface parameters were measured. In particular, surface roughness profiles of three bare or sparsely vegetated fields were measured in the first intensive campaigns. All the characterized fields presented values of the standard deviation of surface heights $(s)$ within the range of validity of the Small Perturbation Model at L-band (i.e., $k s<0.5, k$ being the wavenumber). Furthermore, during each intensive campaign, Time Domain Reflectometry measurements of volumetric soil moisture content were carried out along geolocated transects on the study area. Over wheat fields, more than 370 points, covering a wide range of soil moisture conditions, were sampled. A Bowen Ratio Energy Balance station and a Large Aperture Scintillometer station were installed in a winter wheat field during the campaign. A detailed description of these stations is given in [32]. Finally, meteorologic data were continuously monitored by the weather stations at Görmin $\left(53.98^{\circ} \mathrm{N}, 13.25^{\circ} \mathrm{E}\right)$ and Buchholz $\left(53.94^{\circ} \mathrm{N}, 13.16^{\circ} \mathrm{E}\right)$.

\section{Remotely Sensed Surface SoIL Moisture VALUES}

The developed algorithm transforms a temporal series of L-band HH SAR data into soil moisture values of bare and winter wheat fields. Reference [27] demonstrated that the dominant contribution to L-band wheat backscatter, acquired at $\mathrm{HH}$ polarization and low-medium incidence angles, comes from the ground. This implies that there exists an important sensitivity of L-band SAR signals to soil moisture content during the entire wheat growing season, and that the interaction between the wheat canopy and the SAR signal at $\mathrm{HH}$ polarization can be disregarded. The validity of such an approximation has been confirmed by the analysis of L-band ESAR data acquired during the AgriSAR 2006 campaign [29]. Under these circumstances, the method adopted in the developed retrieval algorithm inverts a surface scattering model, more specifically the Integral Equation Method (IEM) model [33], by means of a constrained optimization technique, integrating a priori information on soil parameters [14]. To improve the robustness and accuracy of the algorithm, the minimization technique has been used to invert a time series of $N$ SAR images instead of a single image [29]. The multitemporal information is beneficial for the accuracy of the retrieved soil moisture content under the condition that the surface roughness remains almost constant during the time span $(T)$ of the $N$ acquisitions. In this case, disregarding the presence of vegetation, and assuming an exponential autocorrelation function [34], the number of surface parameters to be estimated is $N+2(N$ soil moisture values and two surface roughness parameters, namely, the roughness $s$ and the correlation length $l$ ). $N$ equal to one corresponds to the worst ratio 


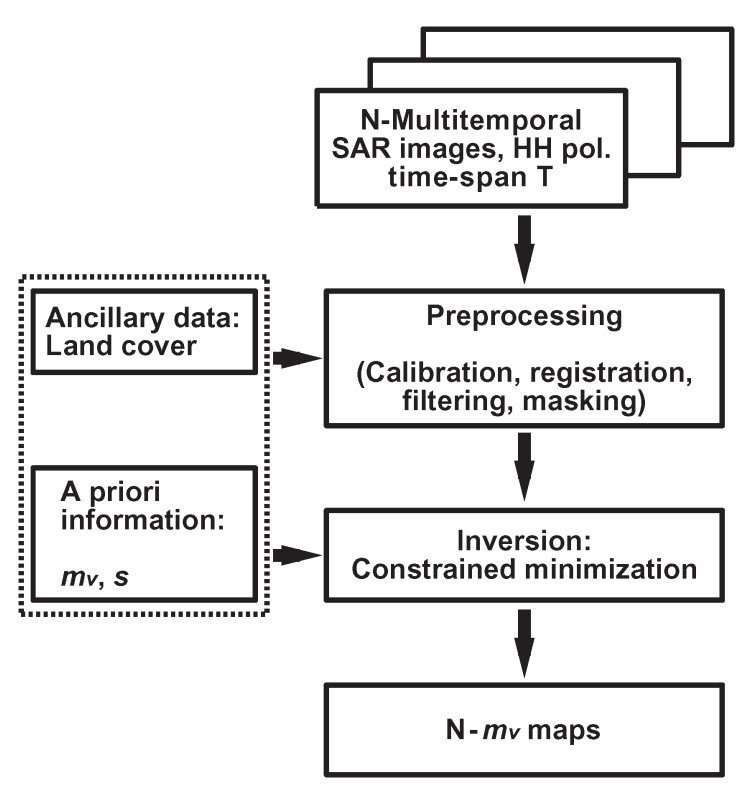

Fig. 1. Flowchart of the soil moisture retrieval algorithm.

(i.e., 1/3) between independent measurements and parameters to be estimated (highly inaccurate retrieval). For large $N$, the ratio tends to one (accurate retrieval). Reference [35] showed that, using three images, the soil moisture content can be retrieved with an rmse of $5 \%$, if the a priori information on soil moisture content is accurate to within approximately $8 \%$.

The 12 soil moisture maps analyzed in this paper were obtained by processing the ESAR images, acquired from April to August 2006, over the DEMMIN site along the West-East track, in four independent runs. This corresponds to a value of three for $N$ and approximately 21 days for $T$. Fig. 1 shows a flowchart of the implemented algorithm. Ancillary information concerning land cover as well as the initial guess values for vertical surface roughness and soil moisture content are required. A priori information concerning soil moisture content was obtained from weekly in situ measurements on one wheat field (i.e., field 230). For the surface roughness, a constant value of $1.5 \mathrm{~cm}$ for $s$ was adopted. The choice of this value is based on the fact that the most likely value for $s$ for agricultural fields ranges between 0.6 and $5 \mathrm{~cm}$ [36], and more specifically, for sown fields, $s$ usually varies between 0.5 and $2.5 \mathrm{~cm}$, and the average value for the latter type of tillage was adopted. Although this choice is arbitrary, it should be noted that this is just an initial guess with a limited influence on the final retrieved values. Concerning the correlation length $l$, no a priori information is used because: 1) it is extremely difficult to provide reliable values of $l$ since this parameter is characterized by a large measurement variability and thus a large uncertainty [34] and 2) in the inversion procedure, the use of $l$ as a free parameter may allow one to better match the observed SAR data with the IEM model [37], [38].

As an example, Fig. 2 shows the estimated map of soil moisture contents on July 5 (i.e., Day of Year 186, during the July intensive campaign). This date was at the end of a very hot and dry period, and field observations confirm the rather uniform very low soil moisture conditions throughout the test site during that period [32]. In order to quantify the accuracy of

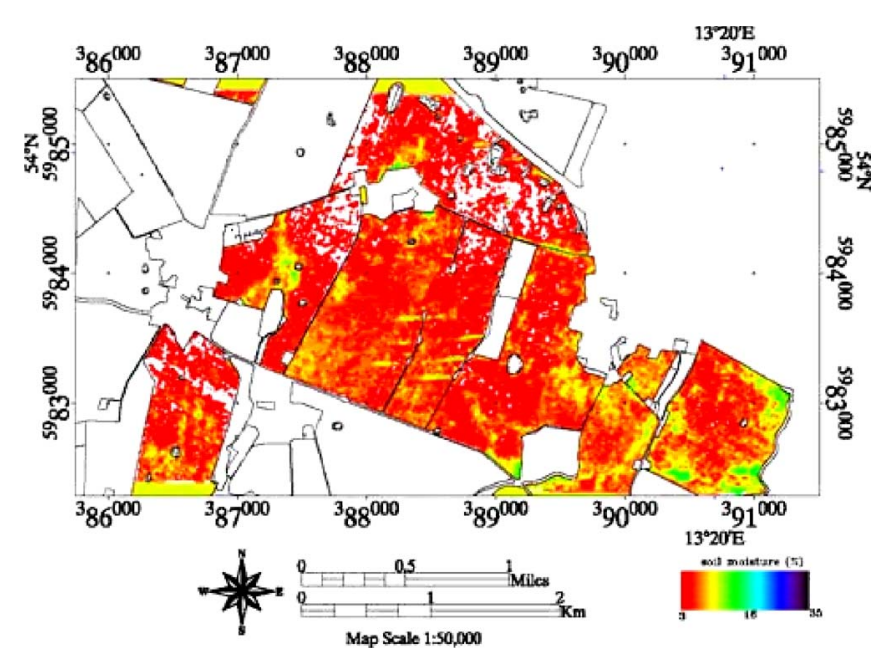

Fig. 2. ESAR derived soil moisture map over the study area on July 5, 2006.

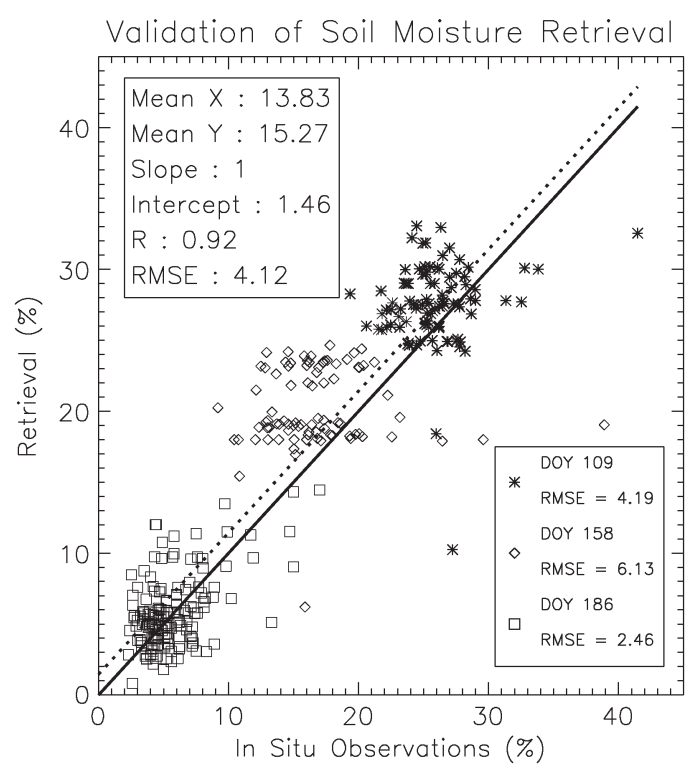

Fig. 3. Validation of the retrieved soil moisture values using the in situ observations. The solid line is the 1:1 line, the dotted line the regression line. The different symbols indicate different dates as explained in the bottom righthand side legend.

the algorithm, the retrieved soil moisture values were compared to the TDR measurements performed during the three intensive campaigns carried out in April, June, and July. Fig. 3 shows the comparison of the SAR retrieved soil moisture values to the in situ TDR observed soil moisture values, estimated on Day of Year 109, 158, and 186. The low bias and rmse, combined with a regression line close to the $1: 1$ line, indicate that the soil moisture values, obtained using this method, are reliable, and can be used for the analysis in the next sections.

\section{Hydrologic MOdEL}

The hydrologic model used in this paper, the TOPLATS, has as its foundation the concept that shallow groundwater gradients set up spatial patterns of soil moisture that influence infiltration and runoff during storm events, and evaporation and drainage between these events. The assumption is made 
that these gradients can be estimated from local topography (through a soil-topographic index [39]). From this foundation, the model was expanded to include infiltration and resistancebased evaporation processes, a surface vegetation layer, and a surface energy balance equation with an improved ground heat flux parameterization, and the effect of atmospheric stability on energy fluxes [26], [40]. The model was originally developed to simulate the surface water and energy balance for warm seasons [26], [40]. Afterward, winter processes (frozen ground and a snow pack), an improved water and energy balance scheme for open water bodies, and a two-layer vegetation parameterization were added [41]. For a detailed model description, we refer to [26], [40], and [41]. Application to the Zwalm catchment [42]-[44], the Upper Kuparuk River Basin in Alaska [45], the Red-Arkansas River Basin [46], [47], the Dill catchment in central Germany [48], and to field experiments such as FIFE [40], BOREAS [49], [50], SGP97 [51], SGP99 [52], SMEX02 [53], and AgriSAR 2006 [32] have shown that the model can adequately simulate surface energy fluxes, soil temperature, and soil moisture.

\section{PARAmeter Estimation Procedure}

\section{A. Mathematical Formulation}

The methodology used to estimate the parameters has been explained in detail in [54]. Only a short description is given here.

The algorithm is based on the equations of the Extended Kalman Filter (EKF). In the system considered, the state vector (consisting of $n$ parameter values) at iteration $k\left(\mathbf{x}_{k}\right)$ is propagated to iteration $k+1$, taking into account the process noise $\mathbf{w}_{k}$

$$
\mathbf{x}_{k+1}=\mathbf{x}_{k}+\mathbf{w}_{k} .
$$

The observation vector at iteration $k$ ( $\mathbf{y}_{k}$, with $m$ observations) is related to the system parameters as follows:

$$
\mathbf{y}_{k}=c\left(\mathbf{x}_{k}, \mathbf{v}_{k}\right)
$$

$\mathbf{v}_{k}$ is the measurement noise. $c$ is a nonlinear function, which relates the observation at iteration $k$ to the parameter values at iteration $k . \mathbf{v}_{k}$ and $\mathbf{w}_{k}$ are assumed to be independent of each other, to be white, with covariances $\mathbf{R}_{k}$ and $\mathbf{Q}_{k}$, respectively.

Equation (2) can be linearized as follows:

$$
\mathbf{y}_{k}=\hat{\mathbf{y}}_{k}^{-}+\mathbf{H}_{k}\left(\mathbf{x}_{k}-\hat{\mathbf{x}}_{k}^{-}\right)+\mathbf{V}_{k} \mathbf{v}_{k}
$$

$\mathbf{x}_{k}$ and $\mathbf{y}_{k}$ are the actual parameter and observation vectors, and $\hat{\mathbf{x}}_{k}^{-}$and $\hat{\mathbf{y}}_{k}^{-}$are the a priori estimates of the parameter and observation vectors (before the parameter update). The Jacobian matrices $\mathbf{H}_{k}$ ( $m$ rows and $n$ columns), and $\mathbf{V}_{k}$ ( $n$ rows and columns) are calculated as follows:

$$
\left\{\begin{array}{l}
\mathbf{H}_{k}[i, j]=\frac{\partial c\left(\hat{\mathbf{x}}_{k}^{-}, \mathbf{0}\right)[i]}{\partial \mathbf{x}[j]} \\
\mathbf{V}_{k}[i, j]=\frac{\partial c\left(\hat{\mathbf{x}}_{k}^{-}, \mathbf{0}\right)[i]}{\partial \mathbf{v}[j]}
\end{array}\right.
$$

The zero means that for the calculation of these partial derivatives a noise level of zero is assumed. $\mathbf{V}_{k}$ is assumed to be the identity matrix, and $\mathbf{H}_{k}$ is calculated numerically.
For our research, the EKF is applied in an iterative manner as follows. For each iteration level $k$, the model is applied for the entire simulation period. The model simulations are stored in the vector $\hat{\mathbf{y}}_{k}^{-}$, and the corresponding observations in the vector $\mathbf{y}$. The system parameter vector $\hat{\mathbf{x}}_{k}$ is propagated from iteration $k-1$ to iteration $k$ as follows:

$$
\hat{\mathbf{x}}_{k}^{-}=\hat{\mathbf{x}}_{k-1}^{+}
$$

Then, using the a posteriori (after the parameter update) error covariance from the previous iteration, the a priori error covariance at the current iteration $\mathbf{P}_{k}^{-}$is calculated

$$
\mathbf{P}_{k}^{-}=\mathbf{P}_{k-1}+\mathbf{Q}_{k-1} \text {. }
$$

The parameter vector and the error covariance are updated as follows:

$$
\left\{\begin{array}{l}
\mathbf{K}_{k}=\mathbf{P}_{k}^{-} \mathbf{H}_{k}^{\mathrm{T}}\left[\mathbf{H}_{k} \mathbf{P}_{k}^{-} \mathbf{H}_{k}^{\mathrm{T}}+\mathbf{R}_{k}\right]^{-1} \\
\hat{\mathbf{x}}_{k}^{+}=\hat{\mathbf{x}}_{k}^{-}+\mathbf{K}_{k}\left(\mathbf{y}_{k}-\hat{\mathbf{y}}_{k}^{-}\right) \\
\mathbf{P}_{k}=\left[\mathbf{I}-\mathbf{K}_{k} \mathbf{H}_{k}\right] \mathbf{P}_{k}^{-}
\end{array}\right.
$$

$\hat{\mathbf{x}}_{k}^{+}$is the a posteriori estimate of the parameter vector. The values of $\hat{\mathbf{x}}_{k}^{+}$are then stored into the parameter vector $\hat{\mathbf{x}}_{k+1}^{-}$, and the algorithm is repeated until convergence is achieved or when a predefined number of iterations has been reached.

The parameter estimation procedure can be applied using either directly observed backscatter coefficients, or inverted soil moisture products. However, (4) and (7) show that, if in both cases the same backscatter model is used, and the gradients and observation errors are calculated correctly, both approaches will lead to the same results. Since it is easier for a modeler to use observations in the same units as the model results (because the need to implement a forward backscatter model is bypassed), we have chosen to use inverted soil moisture values in the parameter estimation procedure.

\section{B. Application to the Test Site}

A sensitivity analysis of the hydrologic model indicated that the three most important soil parameters in the determination of the soil moisture content are the saturated hydraulic conductivity $\left(K_{\mathrm{s}}\right)$, the pore size distribution index $(\lambda)$, and the bubbling pressure $\left(\psi_{\mathrm{c}}\right)$. Therefore, these three parameters were estimated.

Application of the parameter estimation algorithm in a full 3-D manner would require a large parameter vector, with on the order of 100000 entries. This would make the matrix operations [particularly the matrix inversion of (7)] extremely difficult. Therefore, a simplified method was applied.

Measurements indicate that the water table was rather deep below the surface throughout the experiment (on the order of $2 \mathrm{~m}$ ). Lateral water flow thus had a very limited impact on the soil moisture contents of the top soil. For this reason, the calibration procedure was applied to each pixel separately, instead of to the fully distributed simulations. The resulting parameter values were then stored, and a fully distributed model run was then performed using the new parameters. Furthermore, the soil moisture observations of two different pixels were assumed to 
be the same if, for every time step for which remotely sensed soil moisture values were available, the differences between the observations for the two pixels were lower than $2.5 \%$. The parameter estimation procedure thus had to be applied to only one pixel instead of to both. These simplifications resulted in a strong reduction of the required computational effort. Moreover, the parameter estimation procedure was only applied to those pixels for which at least six observations were available, and for which the topographic index was at the most ten, in order to eliminate pixels with a too shallow modeled water table (less than $1 \mathrm{~m}$ ).

The same initial parameter values were used for each pixel. These were 0.5 for $\lambda, 0.3 \mathrm{~m}$ for $\psi_{\mathrm{c}}$, and $10 \mathrm{~mm} \cdot \mathrm{h}^{-1}$ for $K_{\mathrm{s}}$. In order to determine the entries in $\mathbf{R}_{k}$, the standard deviation of the noise in the observations was set to 0.05 volumetric soil moisture. The diagonal entries in $\mathbf{Q}_{k}$ were set to the square of $25 \%$ of their respective parameter value, while the nondiagonal entries were set to zero. $\mathbf{P}_{0}$ was set equal to $\mathbf{Q}_{0}$ (the value of $\mathbf{Q}_{k}$ at the onset of the iteration procedure). The remote-sensing observations are assumed to correspond to the upper $10 \mathrm{~cm}$ of the soil profile. For this reason, they depth of the upper layer in the soil was set to $10 \mathrm{~cm}$.

The parameter estimation procedure was applied using the first nine soil moisture images. In order to validate the obtained parameters, the model was applied using these parameters, and the modeled soil moisture values were compared to the remotely sensed values for the final three images.

\section{Results}

\section{A. Model Initialization}

The meteorological data needed for the model application were provided by the meteorological station at Görmin. The uncalibrated soil parameters were determined based on the texture class following [55]. The land cover parameters for each vegetation class were determined following [40]. For each land cover class LAI values were observed a number of times throughout the study period. These LAI values were assumed to be representative for all fields with the same land cover class and were used as model input. Model simulations were performed with a spatial resolution of $25 \mathrm{~m}$ and a time step of $1 \mathrm{~h}$.

Fig. 4 shows the comparison of the hydrologically modeled soil moisture values to the in situ observations. Comparing these results to the results from Fig. 3, it can be concluded that the remotely sensed soil moisture values are much closer to the observations than the uncalibrated hydrologic model results. These results justify the use of remotely sensed data to optimize the hydrologic model predictions.

Fig. 5 shows the comparison of the modeled soil moisture to the remote-sensing observations for the first three overpasses. Fig. 6 shows the same comparison for overpasses four through six, and Fig. 7 shows this comparison for overpasses seven through nine. These plots show that, while the observed values are well distributed, the simulated values are strongly centered around two values. This can be explained on the one hand by the fact that the soil moisture observations are only available for winter wheat fields, which cancels the land cover type as a potential source of variability in the model results. Further-

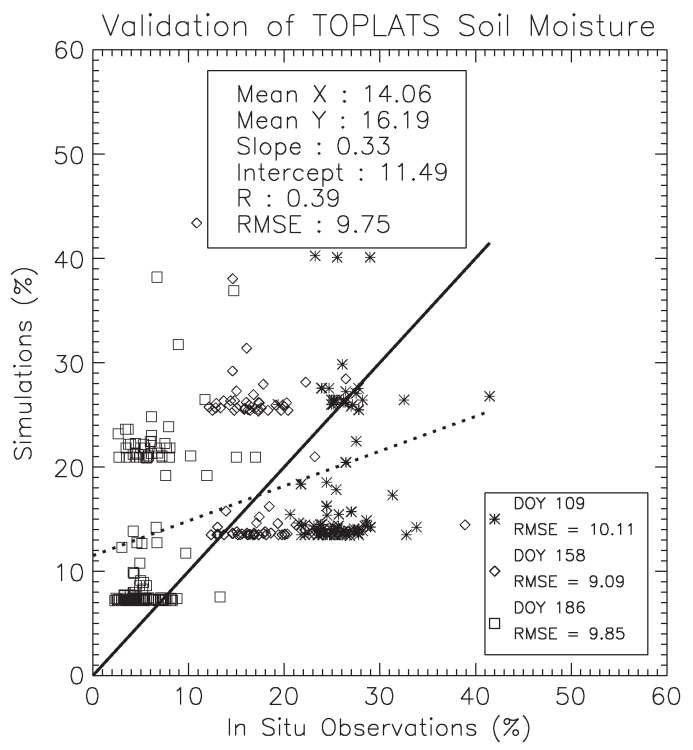

Fig. 4. Validation of the hydrologically modeled soil moisture values using the in situ observations. The solid line is the 1:1 line, the dotted line the regression line. The different symbols indicate different dates as explained in the bottom right-hand side legend.

more, only four different soil texture classes characterized the different pixels for which remotely sensed soil moisture values were available. Table I shows that the two dominant soil texture classes are loamy sand and strong loamy, while the other two soil texture classes are only marginally represented. For each soil class uniform parameters are used throughout the study site, although the variability of soil parameters within a specific soil class can be quite large [55]. This fact, combined with the limited effect of topography in the study site, will cause the modeled soil moisture values to be centered around two different values.

From the results described in this section, it is clear that the use of soil texture class data, combined with a lookup table, is not sufficient to provide acceptable modeled soil moisture values.

\section{B. Calibrated Parameters}

In order to bypass the above described problem, soil parameter values were determined for each pixel, using the algorithm outlined in Section V-B. Fig. 8 shows the spatial distribution of the resulting parameter values and the original soil texture classes.

Examining the top and bottom panels of Fig. 8, one can notice that the values for $K_{\mathrm{s}}$ are consistently lower at the locations for which the original soil texture class is strong loamy. The same observation can be made for $\lambda$, and to a lesser extent for $\psi_{\mathrm{c}}$. Table I shows the spatial averages of these parameters for the entire study area, the standard deviation, and the values from [55] originally used in the model application. Since the texture class "slightly loamy" contains $81 \%$ sand, the value for sand from [55] was used for this class. For the class "strong loamy," the value for loam was used. A number of conclusions can be drawn from this table. First, for all soil texture classes except sandy loam (which is only marginally present), the standard deviations of all parameter values are relatively similar. Furthermore, for $\lambda$, if the values for $\lambda$ are sorted in 

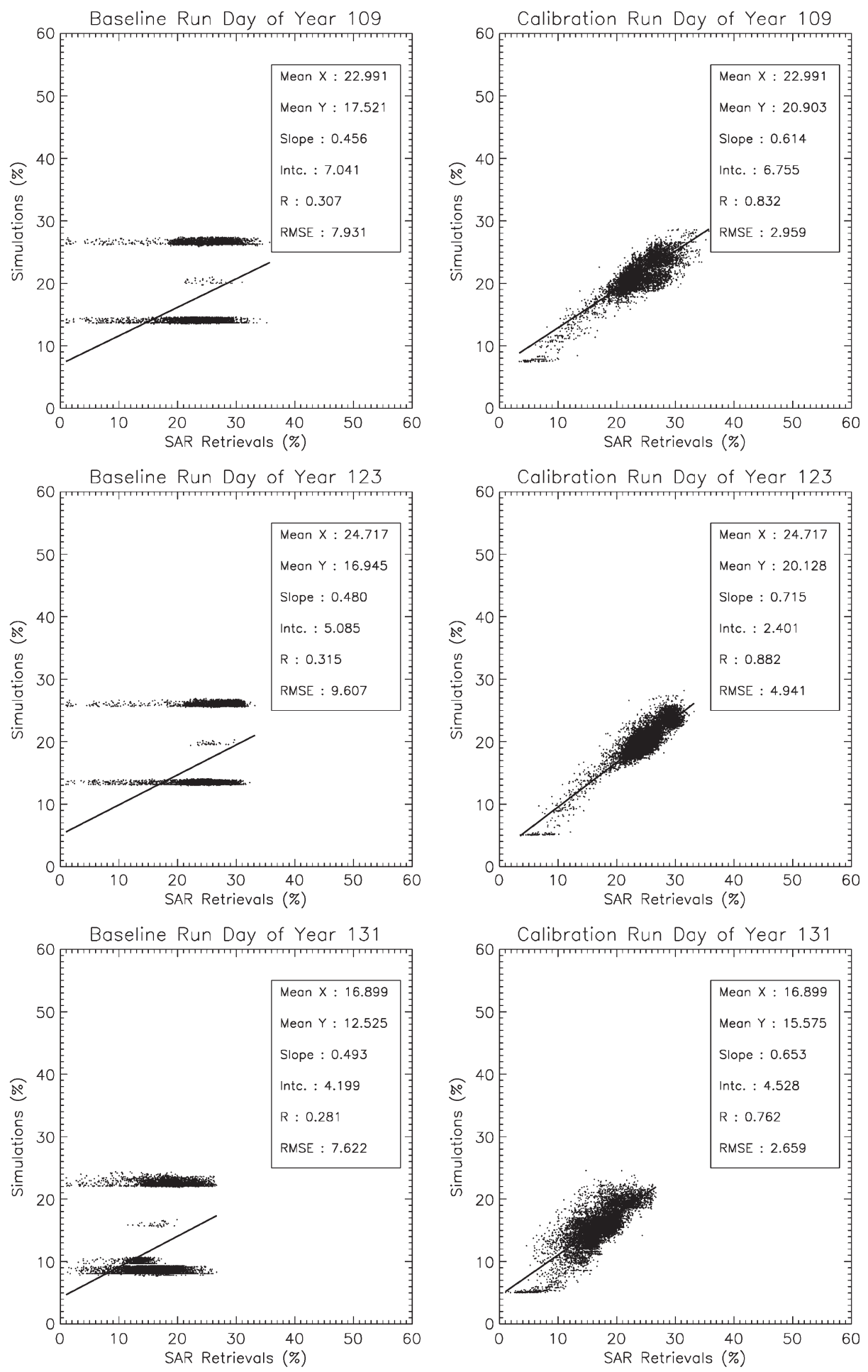

Fig. 5. Comparison of the modeled soil moisture to the observations before and after the calibration procedure for the first three overpasses. The solid line is the regression line.

decreasing order, the resulting order of the soil texture classes is similar for the values from [55] and for the remotely sensed values. However, the remotely sensed values show less variability. These differences in parameter values can be attributed on the one hand to the scale at which they were determined: the values in [55] were obtained at the laboratory scale, while the retrieved parameters in this paper are valid for a pixel resolution of $25 \mathrm{~m}$. As stated in the introduction, the scale at which parameter values were obtained can have a strong influence on the parameter values themselves. Furthermore, the simplification of the flow processes in the unsaturated zone adapted by TOPLATS will also have an impact on the retrieved soil parameters. More specifically, approximate analytical solutions to the Richards equation are used to model the flow of water between the different soil layers. This implies that the use of measured soil parameters will lead to erroneous soil moisture 

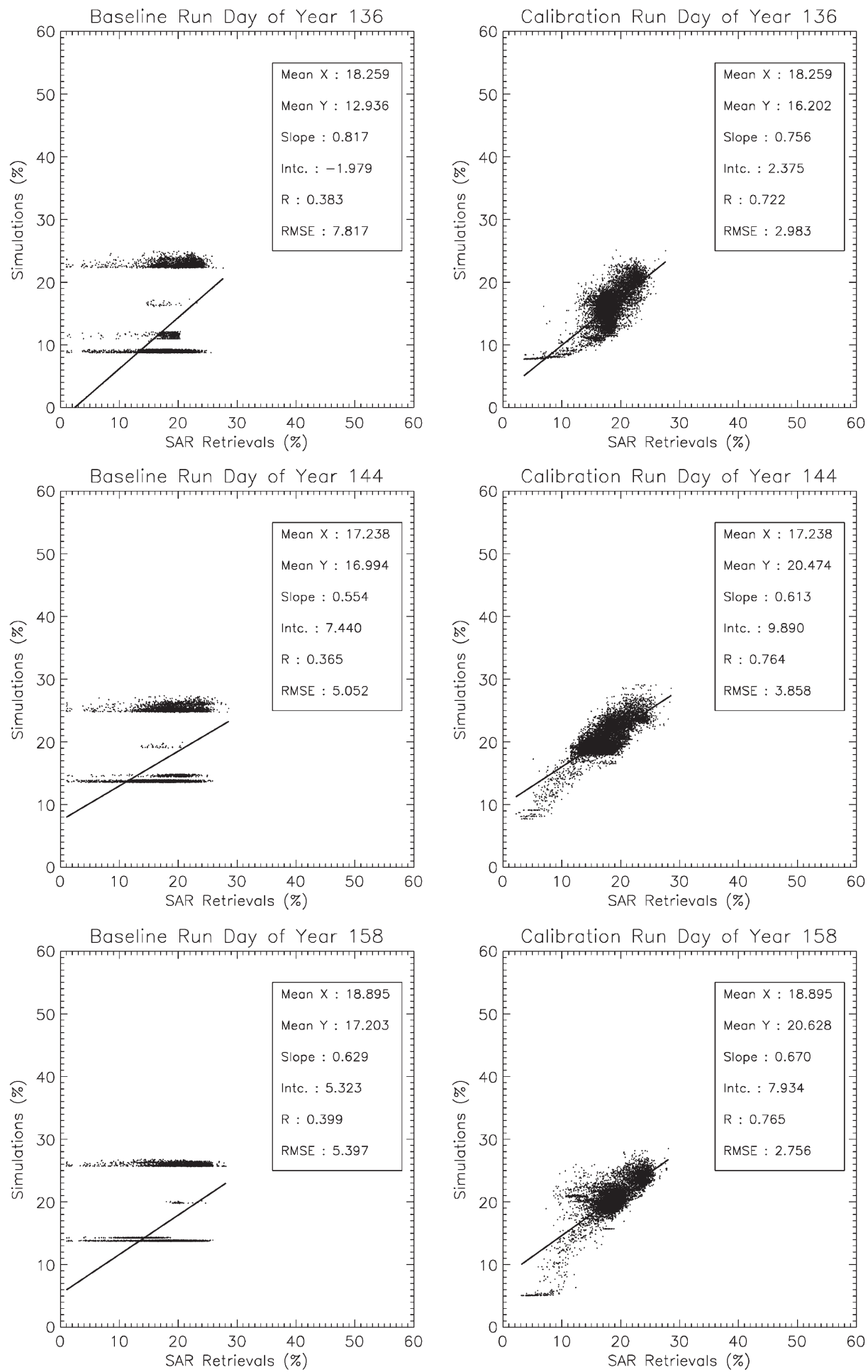

Fig. 6. Comparison of the modeled soil moisture to the observations before and after the calibration procedure for overpasses four through six. The solid line is the regression line.

values. Consequently, if these parameters are estimated using observed soil moisture data, the resulting parameter values will be different from their true values.

The same conclusion can be drawn for the $K_{\mathrm{s}}$ values, but not for $\psi_{\mathrm{c}}$, for which the remotely sensed values for the strong loamy texture class are an exception.

Fig. 9 shows the relationship between the texture class and the soil parameter value for each individual field. For all three parameters, the values for the class "strong loamy" are almost consistently the lowest. For the hydraulic conductivity and the pore size distribution index, this is in agreement with the values from [55], but not for the bubbling pressure. For the other classes, the behavior is not as clear, but this can be explained by their textural composition. Table II shows that for all classes except "strong loamy" the textural composition is relatively similar. It can thus be expected that the retrieved parameter 

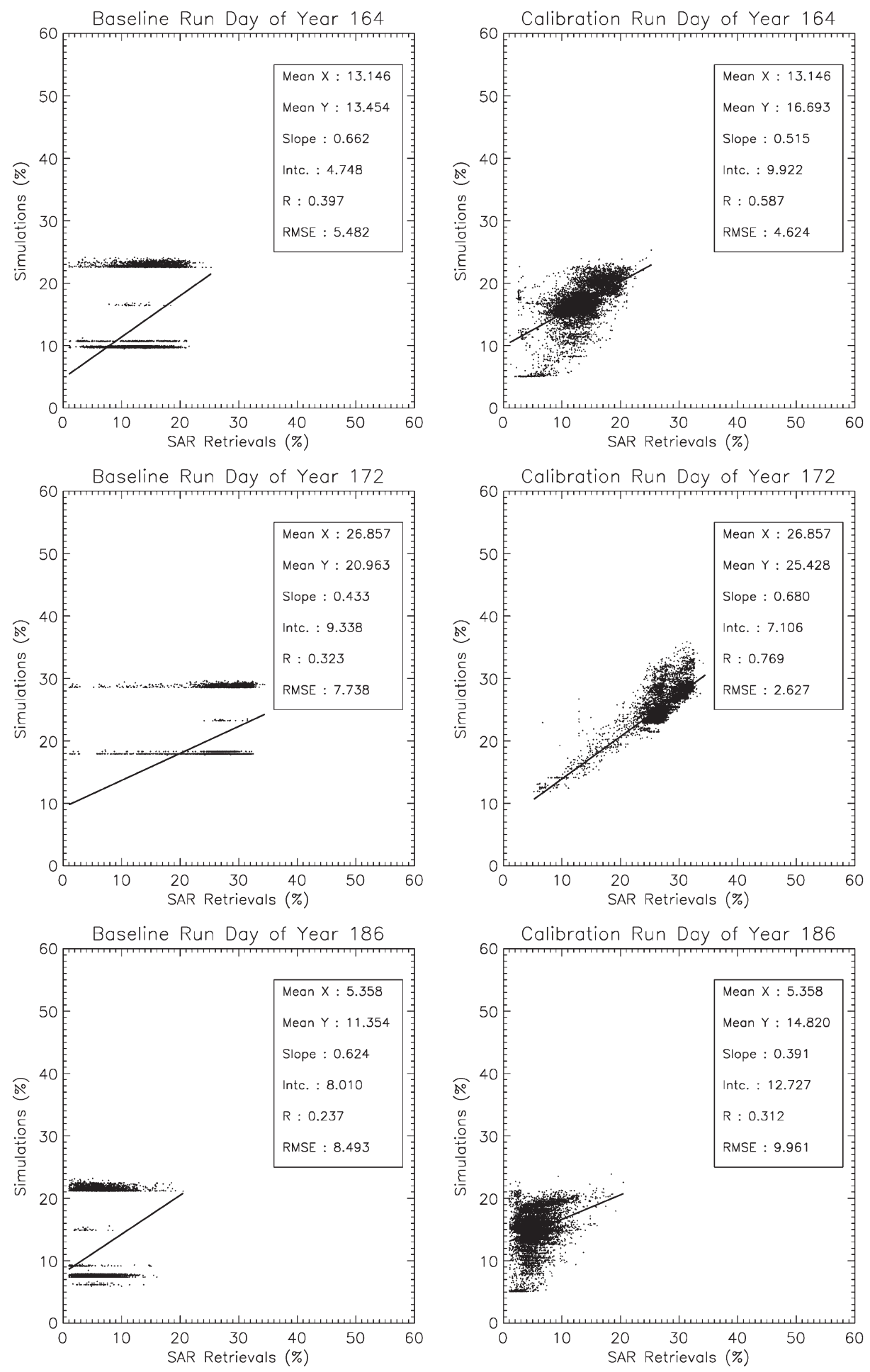

Fig. 7. Comparison of the modeled soil moisture to the observations before and after the calibration procedure for overpasses seven through nine. The solid line is the regression line.

values among these three classes will be more similar than the values of the "strong loamy" class. If the original soil texture classes are lumped into sandy or loamy, a clear distinction between the retrieved values for these classes can be observed.

A general conclusion from Table I and Fig. 9 is, thus, that a relationship exists between the texture class and the calibrated soil parameter values. For the hydraulic conductivity and the pore size distribution index, this relationship is similar as for laboratory values, but for the bubbling pressure an inverse relationship has been found.

\section{Calibration Run}

The calibrated parameters were then used in a final model application. Figs. 5-7 show the comparison of the modeled soil moisture values using the calibrated soil parameters to the 
TABLE I

Spatial Mean and Standard Deviation for all Parameters Throughout the Study Area. $\lambda$ is the Pore Size Distribution Index, $\psi_{\mathrm{c}}$ the Bubbling Pressure, and $K_{\mathrm{s}}$ The Saturated Hydraulic Conductivity. N Stands for the Number of PiXels Within the Class, RBS FOR THE RAWLS et al. [1982] VALUEs, $\mu$ FOR THE AVERAGE OF THE RETRIEVEd PARAMETER VALUES, AND $\sigma$ FOR THE STANDARD DEVIATION

\begin{tabular}{lcccccccccc}
\hline Soil Class & $\mathrm{N}$ & \multicolumn{3}{c}{$\lambda(-)$} & \multicolumn{3}{c}{$\psi_{\mathrm{c}}(\mathrm{m})$} & \multicolumn{4}{c}{$k_{s}\left(\mathrm{~mm} \mathrm{~h}^{-1}\right)$} \\
& & RBS & $\mu$ & $\sigma$ & RBS & $\mu$ & $\sigma$ & RBS & $\mu$ & $\sigma$ \\
\hline Slightly Loamy & 490 & 0.694 & 0.654 & 0.476 & 0.160 & 0.417 & 0.139 & 21.000 & 12.744 & 5.926 \\
Loamy Sand & 8330 & 0.553 & 0.608 & 0.403 & 0.206 & 0.440 & 0.148 & 6.110 & 12.161 & 4.851 \\
Strong Loamy & 2701 & 0.252 & 0.471 & 0.459 & 0.401 & 0.359 & 0.112 & 1.320 & 10.165 & 5.080 \\
Sandy Loam & 44 & 0.378 & 0.525 & 0.101 & 0.302 & 0.446 & 0.160 & 2.590 & 11.148 & 3.366 \\
\hline
\end{tabular}

\section{$\mathrm{Ks}(\mathrm{mm} / \mathrm{h})$}
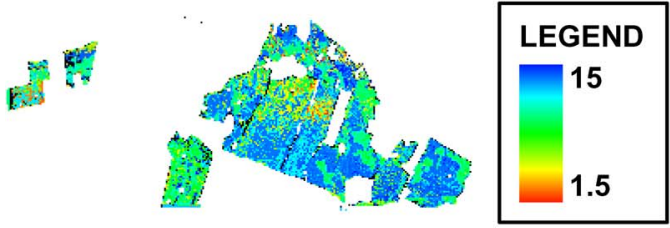

$\lambda(-)$
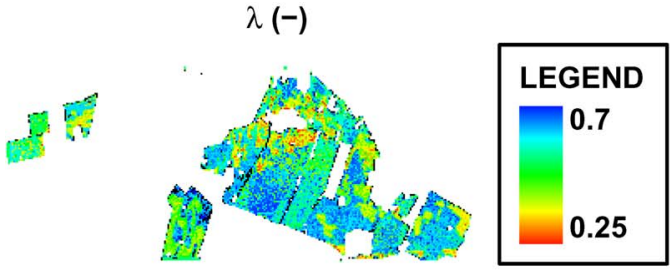

$\psi c(m)$
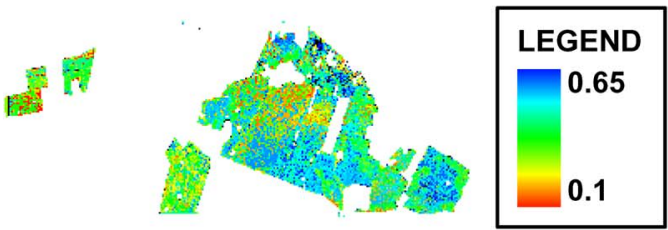

Soil Texture Class

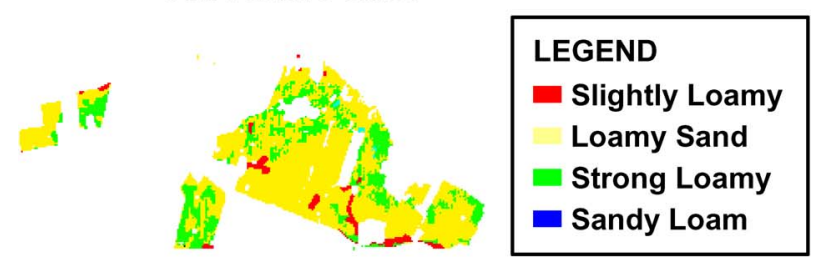

Fig. 8. Resulting soil parameters from the parameter estimation procedure over the test site.

remote-sensing observations. As can be expected, a strong improvement in the modeled soil moisture values can be observed. Since the remotely sensed soil moisture values are prone to degree of uncertainty on the order of 5\% (see Fig. 3), it can be expected that the rmse between the modeled and the remotely sensed soil moisture values will be of the same order. Even though this rmse for Day of Year 186 is almost 10\%, the combined rmse for all nine overpasses is $4.62 \%$, with an average remote-sensing value of $16.38 \%$, and an average modeled value of $16.93 \%$. The slightly worse model performance on Day of Year 186 can be explained by the fact that very low soil moisture conditions were obtained only at the end of the calibration period. Only one date with very low soil moisture contents was thus used in the parameter estimation. It is therefore not surprising that, at the onset of the dry period at the end of the calibration period, the model performs slightly worse. However, the extra validation described in the next paragraph shows that during this dry period the model performance is similar as for wetter days. It can thus be concluded that the estimated soil parameters lead to modeled soil moisture values that are of the same accuracy as the remote-sensing observations with which they were obtained.

Fig. 10 shows the comparison of the modeled soil moisture values to the observations, for the three overpasses that were not used in the parameter estimation. For day 193, a strong reduction in the rmse can be observed. For the two other days, the calibration procedure does not significantly alter the rmse. However, it should be noted that the rather low soil moisture values resulted in a low value of the rmse before the calibration. For these two days, the regression line close to the 1:1 line indicates that the spatial variability in the surface soil moisture content is better matched.

\section{CONCLUSION}

A methodology has been developed, using remotely sensed soil moisture values and hydrologic modeling, to estimate soil hydraulic parameters in a spatially distributed manner. When the hydrologic model uses average soil parameters determined using soil texture classes, a lack of spatial variability in the model results has been obtained. When remotely sensed soil moisture values are used to estimate the three most important soil parameters (the hydraulic conductivity, the bubbling pressure, and the pore size distribution index), a relationship between the original texture classes and the retrieved parameter values can be observed at the level of the study area. This relationship is in agreement with the relationships found in [55], except for the bubbling pressure. The variation of the parameter values obtained through remote sensing between the texture classes is not as strong as for the values obtained by [55]. This can be attributed on the one hand to the scale at which the parameters have been obtained. While the values from [55] have been obtained at the laboratory scale, the values obtained in this paper are obtained at a pixel resolution of $25 \mathrm{~m}$. Furthermore, the simplifications of the unsaturated zone processes adapted by the hydrologic model will also have an impact on the retrieved parameter values. At the field level, the same relationship between the texture class and the retrieved parameters has been found when the soils are subdivided into classes predominantly consisting of loam or sand. 

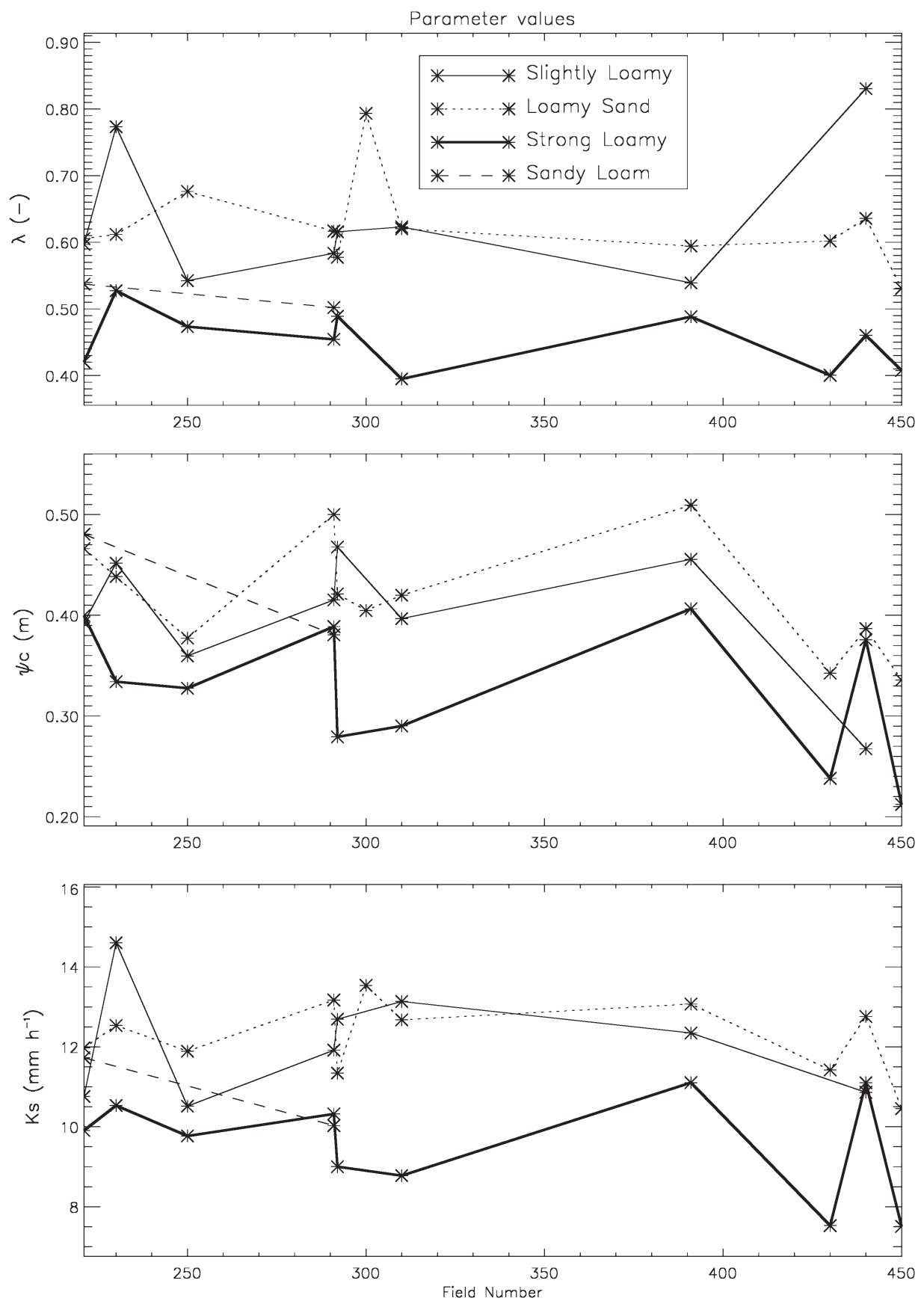

Fig. 9. Soil parameters per field and per original texture class. The thick solid line is the loamy class, the other lines are the sandy classes.

TABLE II

TEXTURAL COMPOSITION OF THE FOUR SOIL TeXture Classes in the STUdy AREa

\begin{tabular}{lccc}
\hline Texture Class & \% Clay & \% Silt & \% Sand \\
\hline Slightly Loamy & 4 & 15 & 81 \\
Loamy Sand & 7 & 25 & 68 \\
Strong Loamy & 9 & 75 & 16 \\
Sandy Loam & 12 & 25 & 63 \\
\hline
\end{tabular}

Overall, this paper leads to the conclusion that the possibility exists to retrieve soil hydraulic parameters through a combination of remote sensing and hydrologic modeling. In order for hydrologic models to operate optimally, accurate meteorologic forcings are of primary importance, but it will probably never be possible to provide these forcings with a uniform accuracy in a spatially distributed way. Therefore, optimization using remotesensing data is needed. Although the parameter values may be different than values found in the literature, this difference can be attributed to the difference in scale at which the parameters are measured, and to the effects of a simplification of the physical reality by the model. Since hydrologic models generally need to be applied at a spatial scale that is much larger than the laboratory scale, the methodology described in this paper could serve as a basis to derive soil physical parameters at multiple spatial scales. Future research will focus on the application of the proposed methodology using different hydrologic models using remotely sensed soil moisture contents at different spatial 

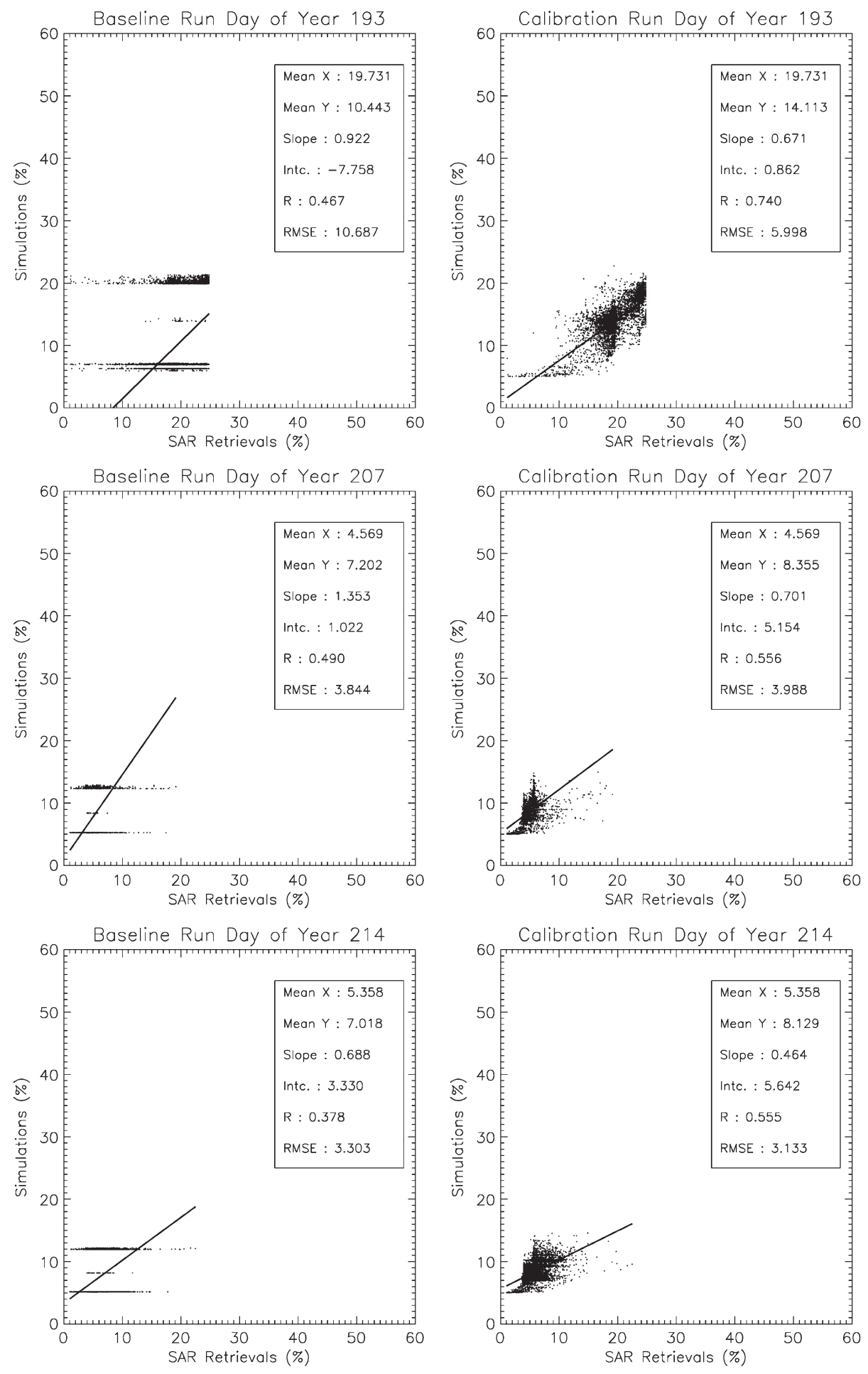

Fig. 10. Comparison of the modeled soil moisture to the observations before and after the calibration procedure for the three overpasses used for model validation. The solid line is the regression line.

scales, in order to assess an impact of the effects of model structure and spatial scale on the estimated soil parameters.

\section{ACKNOWLEDGMENT}

The authors would also like to thank the entire AgriSAR team for their help in the collection and distribution of the various data sets.

\section{REFERENCES}

[1] F. T. Ulaby, R. K. Moore, and A. K. Fung, "Microwave remote sensing, active and passive," in From Theory to Applications, vol. III. Norwood, MA: Artech House, 1986.

[2] P. Ferrazzoli, S. Paloscia, P. Pampaloni, G. Schiavon, S. Sigismondi, and D. Solimini, "The potential of multifrequency polarimetric SAR in assessing agricultural and arboreous biomass," IEEE Trans. Geosci. Remote Sens., vol. 35, no. 1, pp. 5-17, Jan. 1997.

[3] G. Macelloni, S. Paloscia, P. Pampaloni, F. Marliani, and M. Gai, "The relationship between the backscattering coefficient and the biomass of 
narrow and broad leaf crops," IEEE Trans. Geosci. Remote Sens., vol. 39, no. 8, pp. 1655-1661, Apr. 2001.

[4] F. Mattia, T. Le Toan, G. Picard, F. I. Posa, A. D’Alessio, C. Notarnicola, A. M. Gatti, M. Rinaldi, G. Satalino, and G. Pasquariello, "Multitemporal C-band radar measurements on wheat fields," IEEE Trans. Geosci. Remote Sens., vol. 41, no. 7, pp. 1551-1560, Jul. 2003.

[5] H. Skriver, M. T. Svendsen, and A. G. Thomsen, "Multitemporal C- and L-band polarimetric signatures of crops," IEEE Trans. Geosci. Remote Sens., vol. 37, no. 5, pp. 2413-2429, Sep. 1999.

[6] X. Blaesa, P. Defourny, U. Wegmüller, A. Della Vecchia, L. Guerriero, and P. Ferrazzoli, "C-band polarimetric indexes for maize monitoring based on a validated radiative transfer model," IEEE Trans. Geosci. Remote Sens., vol. 44, no. 4, pp. 791-800, Apr. 2006.

[7] K. Stankiewicz, "The efficiency of crop recognition on ENVISAT ASAR images in two growing seasons," IEEE Trans. Geosci. Remote Sens., vol. 44, no. 4, pp. 806-814, Apr. 2006.

[8] C. Notarnicola and F. Posa, "Inferring vegetation water content from C- and L-band SAR images," IEEE Trans. Geosci. Remote Sens., vol. 45, no. 10 , pp. $3165-3171$, Oct. 2007.

[9] H. Skriver, F. Mattia, G. Satalino, A. Balenzano, V. R. N. Pauwels, N. Verhoest, and M. Davidson, "Land-cover classification from SAR data for hydrological modelling," in Proc. 5th Int. Symp. BioGeoSAR, Bari, Italy, 2007.

[10] G. H. Griffiths and M. G. Wooding, "Temporal monitoring of soil moisture using ERS-1 SAR data," Hydrol. Process., vol. 10, no. 9, pp. 1127-1138, Sep. 1996.

[11] G. Satalino, F. Mattia, M. W. J. Davidson, T. Le Toan, G. Pasquariello, and M. Borgeaud, "On current limits of soil moisture retrieval from ERS-SAR data," IEEE Trans. Geosci. Remote Sens., vol. 40, no. 11, pp. 2438-2447, Nov. 2002.

[12] J. Álvarez-Mozos, J. Casali, M. Gonzalez-Audicana, and N. E. C. Verhoest, "Correlation between ground measured soil moisture and RADARSAT-1 derived backscattering coefficient over an agricultural catchment of Navarre (North of Spain)," Biosyst. Eng., vol. 92, no. 1, pp. 119-133, Sep. 2005.

[13] J. Álvarez-Mozos, J. Casali, M. Gonzalez-Audicana, and N. E. C. Verhoest, "Assessment of the operational applicability of RADARSAT-1 data for surface soil moisture estimation," IEEE Trans. Geosci. Remote Sens., vol. 44, no. 4, pp. 913-924, Apr. 2006.

[14] F. Mattia, G. Satalino, L. Dente, and G. Pasquariello, "Using a priori information to improve soil moisture retrieval from ENVISAT ASAR AP data in semiarid regions," IEEE Trans. Geosci. Remote Sens., vol. 44, no. 4, pp. 900-912, Apr. 2006.

[15] N. E. C. Verhoest, B. De Baets, F. Mattia, G. Satalino, C. Lucau, and P. Defourny, "A possibilistic approach to soil moisture retrieval from ERS synthetic aperture radar backscattering under soil roughness uncertainty," Water Resour. Res., vol. 43, no. 7, p. W07 435, Jul. 2007.

[16] P. R. Houser, W. J. Shuttleworth, J. S. Famiglietti, H. V. Gupta, K. H. Syed, and D. C. Goodrich, "Integration of soil moisture remote sensing and hydrologic modeling using data assimilation," Water Resour. Res., vol. 34, no. 12, pp. 3405-3420, Aug. 1998.

[17] M. S. Moran, C. D. Peters-Litard, J. M. Watts, and S. McElroy, "Estimating soil moisture at the watershed scale with satellite-based radar and land surface models," Can. J. Remote Sens., vol. 30, no. 5, pp. 805-826, 2004.

[18] W. Wagner, G. Blöschl, P. Pampaloni, J. C. Calvet, B. Bizzarri, J. P. Wigneron, and Y. Kerr, "Operational readiness of microwave remote sensing of soil moisture for hydrologic applications," Nord. Hydrol., vol. 38, no. 1, pp. 1-20, 2007.

[19] N. M. Mattikalli, E. T. Engman, T. J. Jackson, and L. R. Ahuja, "Microwave remote sensing of temporal variations of brightness temperature and near-surface soil water content during a watershed-scale field experiment, and its application to the estimation of soil physical properties," Water Resour. Res., vol. 34, no. 9, pp. 2289-2300, Feb. 1998.

[20] D. H. Chang, R. Kothari, and S. Islam, "Classification of soil texture using remotely sensed brightness temperature over the Southern Great Plains," IEEE Trans. Geosci. Remote Sens., vol. 41, no. 3, pp. 664-674, Mar. 2003.

[21] C. W. Rovey, "Digital simulation of the scale effect in hydraulic conductivity," Hydrogeol. J., vol. 6, no. 2, pp. 216-225, Aug. 1998.

[22] P. M. Atkinson, "Optimal ground-based sampling for remote sensing investigations: Estimating the regional mean," Int. J. Remote Sens., vol. 12, no. 3, pp. 559-567, Mar. 1991.

[23] P. J. van Oevelen, "Soil moisture variability: A comparison between detailed field measurements and remote sensing measurement techniques," Hydrol. Sci. J., vol. 43, no. 4, pp. 511-520, 1998.

[24] J. A. Santanello, Jr., C. D. Peters-Lidard, M. E. Garcia, D. M. Mocko, M. A. Tischler, M. S. Moran, and D. P. Thoma, "Using remotely-sensed estimates of soil moisture to infer soil texture and hydraulic properties across a semi-arid watershed," Remote Sens. Environ., vol. 110, no. 1, pp. 79-97, Sep. 2007.

[25] K. J. Beven and M. J. Kirkby, "A physically based, variable contributing area model of basin hydrology," Hydrol. Sci. Bull., vol. 24, no. 1, pp. 43-69, 1979.

[26] J. S. Famiglietti and E. F. Wood, "Multiscale modeling of spatially variable water and energy balance processes," Water Resour. Res., vol. 30, no. 11, pp. 3061-3078, Jun. 1994.

[27] A. Touré, K. P. B. Thomson, G. Edwards, R. J. Brown, and B. G. Brisco, "Adaptation of the MIMICS backscattering model to the agricultural context-wheat and canola at L and C bands," IEEE Trans. Geosci. Remote Sens., vol. 32, no. 1, pp. 47-61, Jan. 1994.

[28] F. Mattia, G. Satalino, A. Balenzano, V. R. N. Pauwels, N. Verhoest, H. Skriver, and M. Davidson, "Exploiting L-band SAR data for the improvement of surface process modelling," in Proc. 5th Int. Symp. BioGeoSAR, Bari, Italy, 2007.

[29] F. Mattia, G. Satalino, and A. Balenzano, "Retrieval of soil moisture content using PALS data," in Proc. 1st Joint PI Symp. ALOS Data Nodes ALOS Sci. Program, Kyoto, Japan, Nov. 19-23, 2007.

[30] I. Hajnsek, R. Bianchi, M. Davidson, G. D’Urso, J. A. Gomez-Sanchez, A. Hausold, R. Horn, J. Howse, A. Loew, J. M. Lopez-Sanchez, R. Ludwig, J. A. Martinez-Lozano, F. Mattia, E. Miguel, J. Moreno, V. R. N. Pauwels, T. Ruhtz, C. Schmullius, H. Skriver, J. A. Sobrino, W. Timmermans, C. Wloczyk, and M. Wooding, "AGRISAR optical and radar campaign, final report," Eur. Space Agency, Paris, France, Tech. Rep. ESA Contract 19974/06/I/LG, 2007.

[31] A. Ferniández-Renau, J. A. Gómez, and E. de Miguel, "The INTA AHS system. Sensors, systems, and next-generation satellites," in Proc. Int. Soc. Opt. Eng. SPIE, 2005, vol. 5978, pp. 471-478.

[32] V. R. N. Pauwels, W. Timmermans, and A. Loew, "Comparison of the estimated water and energy budgets of a large winter wheat field during AgriSAR 2006 by multiple sensors and models," J. Hydrol., vol. 349, no. 3/4, pp. 425-440, Feb. 2008.

[33] A. K. Fung, Z. Li, and K. S. Chen, "Backscattering from a randomly rough dielectric surface," IEEE Trans. Geosci. Remote Sens., vol. 30, no. 2, pp. 356-369, Mar. 1992.

[34] M. Callens, N. E. C. Verhoest, and M. W. J. Davidson, "Parameterization of tillage-induced single-scale soil roughness from 4-m profiles," IEEE Trans. Geosci. Remote Sens., vol. 44, no. 4, pp. 878-888, Apr. 2006.

[35] F. Mattia, G. Satalino, A. Balenzano, V. R. N. Pauwels, N. E. C. Verhoest, and H. Skriver, "Exploiting L-band SAR data for the improvement of surface process modeling," Eur. Space Agency, Paris, France, Tech. Rep. ESA-ESTEC 19558/NL/HE, 2008.

[36] T. J. Jackson, H. McNairn, M. A. Weltz, B. Brisco, and R. Brown, "First order surface roughness correction of active microwave observations for estimating soil moisture," IEEE Trans. Geosci. Remote Sens., vol. 35, no. 4, pp. 1065-1069, Jul. 1997.

[37] N. Baghdadi, C. King, A. Chanzy, and J. P. Wigneron, "An empirical calibration of the integral equation model based on SAR data, soil moisture and surface roughness measurement over bare soils," Int. J. Remote Sens., vol. 23, no. 20, pp. 4325-4340, 2002.

[38] R. Bryant, M. S. Moran, D. P. Thoma, C. D. Holifield Collins, S. Skirvin, M. Rahman, K. Slocum, P. Starks, D. Bosch, and M. P. Gonález Dugo, "Measuring surface roughness height to parameterize radar backscatter models for retrieval of surface soil moisture," IEEE Geosci. Remote Sens. Lett., vol. 4, no. 1, pp. 137-141, Jan. 2007.

[39] M. Sivapalan, K. Beven, and E. F. Wood, "On hydrologic similarity, 2, a scaled model for runoff prediction," Water Resour. Res., vol. 23, no. 12, pp. 2266-2278, 1987.

[40] C. D. Peters-Lidard, M. S. Zion, and E. F. Wood, "A soil-vegetationatmosphere transfer scheme for modeling spatially variable water and energy balance processes," J. Geophys. Res., vol. 102, no. D4, pp. 4303-4324, 1997.

[41] V. R. N. Pauwels and E. F. Wood, "A soil-vegetation-atmosphere transfer scheme for the modeling of water and energy balance processes in high latitudes 1. Model improvements ," J. Geophys. Res., vol. 104, no. D22, pp. 27 811-27 822, Jan. 1999.

[42] V. R. N. Pauwels, R. Hoeben, N. E. C. Verhoest, and F. P. De Troch, "The importance of the spatial patterns of remotely sensed soil moisture in the improvement of discharge predictions for small-scale basins through data assimilation," J. Hydrol., vol. 251, no. 1/2, pp. 88-102, 2001.

[43] V. R. N. Pauwels, R. Hoeben, N. E. C. Verhoest, F. P. De Troch, and P. A. Troch, "Improvement of TOPLATS-based discharge predictions through assimilation of ERS-based remotely sensed soil moisture values," Hydrol. Process., vol. 16, no. 5, pp. 995-1013, Jan. 2002.

[44] V. R. N. Pauwels and G. J. M. De Lannoy, "Improvement of modeled soil wetness conditions and turbulent fluxes through the assimilation 
of observed discharge," J. Hydrometeorol., vol. 7, no. 3, pp. 458-477, Jun. 2006.

[45] S. T. Dery, W. T. Crow, M. Stieglitz, and E. F. Wood, "Modeling snowcover heterogeneity over complex arctic terrain for regional and global climate models," J. Hydrometeorol., vol. 5, no. 1, pp. 33-48, Feb. 2004.

[46] W. T. Crow, M. Drusch, and E. F. Wood, "An observation system simulation experiment for the impact of land surface heterogeneity on AMSR-E soil moisture retrievals," IEEE Trans. Geosci. Remote Sens., vol. 39, no. 8, pp. 1622-1632, Aug. 2001.

[47] W. T. Crow and E. F. Wood, "The value of coarse-scale soil moisture observations for regional surface energy balance modeling," J. Hydrometeorol., vol. 3, no. 4, pp. 467-482, Aug. 2002.

[48] H. Bormann, "Impact of spatial data resolution on simulated catchment water balances and model performance of the multi-scale TOPLATS model," Hydrol. Earth Syst. Sci., vol. 10, no. 2, pp. 165-179, 2006.

[49] V. R. N. Pauwels and E. F. Wood, "A soil-vegetation-atmosphere transfer scheme for the modeling of water and energy balance processes in high latitudes 2. Application and validation," J. Geophys. Res., vol. 104, no. D22, pp. 27 823-27 839, 1999.

[50] V. R. N. Pauwels and E. F. Wood, "The importance of misclassifications and spatial resolution of land cover data in the uncertainty in model results over boreal ecosystems," J. Hydrometeorol., vol. 1, no. 3, pp. 255-266, 2000.

[51] W. T. Crow and E. F. Wood, "The assimilation of remotely sensed soil brightness temperature imagery into a land surface model using Ensemble Kalman filtering: A case study based on ESTAR measurements during SGP97," Adv. Water Resour., vol. 26, no. 2, pp. 137-149, 2003.

[52] H. Gao, E. F. Wood, M. Drusch, W. T. Crow, and T. J. Jackson, "Using a microwave emission model to estimate soil moisture from ESTAR observations during SGP99," J. Hydrometeorol., vol. 5, no. 1, pp. 49-63, Feb. 2004.

[53] W. T. Crow, S. T. K. Chan, D. Entekhabi, P. R. Houser, A. Y. Hsu, T. J. Jackson, E. G. Njoku, P. E. O'Neill, J. C. Shi, and X. W. Zhan, "An observing system simulation experiment for Hydros radiometer-only soil moisture products," IEEE Trans. Geosci. Remote Sens., vol. 43, no. 6, pp. 1289-1303, Jun. 2005.

[54] M. Goegebeur and V. R. N. Pauwels, "Improvement of the PEST parameter estimation algorithm through Extended Kalman Filtering," J. Hydrol., vol. 337, no. 3/4, pp. 436-451, Apr. 2007

[55] W. J. Rawls, D. L. Brakensiek, and K. E. Saxton, "Estimation of soil water properties," Trans. Amer. Soc. Civ. Eng., vol. 25, no. 5, pp. 1316-1320, 1982.

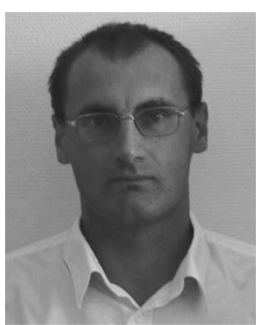

Valentijn R. N. Pauwels received the M.Sc. degree of engineer in agricultural sciences from Ghent University, Gent, Belgium, in 1994 and the Ph.D. degree in civil engineering and operations research from Princeton University, Princeton, NJ, in 1999.

From 1999 to 2004, he was a Postdoctoral Research Associate with the Laboratory of Hydrology and Water Management, Ghent University, at which he became an Associate Professor in 2005. His major research interest is hydrologic model development and optimization.

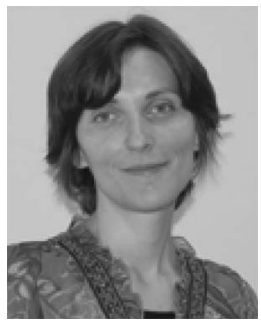

Anna Balenzano received the Laurea degree (cum laude) in physics from the University of Bari, Bari, Italy, in 2003, where she collaborated with the Astroparticle Physics Group, and the Master's degree in information technology from the University of Benevento, Benevento, Italy, in 2004. Since 2006, she is currently working toward the Ph.D. degree in physics with a Grant from the Istituto di Studi sui Sistemi Intelligenti per l'Automazione, Consiglio Nazionale delle Ricerche, Bari.

During the summer of 2005, she was with the INTEC Services web design/development team in Glasgow, Scotland, as participant to the European Community's Vocational Training Programme (LEONARDO). Her research focuses on direct modeling of electromagnetic scattering from vegetated soils and interpretation of synthetic aperture radar data acquired on agricultural sites.

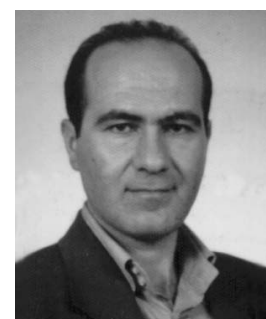

Giuseppe Satalino received the Laurea degree in computer science (cum laude) from the University of Bari, Bari, Italy, in 1991.

In the same year, he was a Summer Student with the European Organization for Nuclear Research, Geneva, Switzerland, where he worked on applications of neural networks to high-energy physics. From 1993 to 1996, he was grantholder of Alenia and Consiglio Nazionale delle Ricerche (CNR). Since 1996, he has been with the Istituto di Studi sui Sistemi Intelligenti per l'Automazione, CNR, Bari $\mathrm{He}$ worked in several national and international research projects concerning image processing, data classification, and remote-sensing applications. He participated in several synthetic aperture radar (SAR) and ground radar experiments for studies concerning the use of remote sensing for agricultural and hydrologic applications. His main research field concerns data classification techniques and methods for the retrieval of geophysical parameters from SAR and optical remote-sensed data.

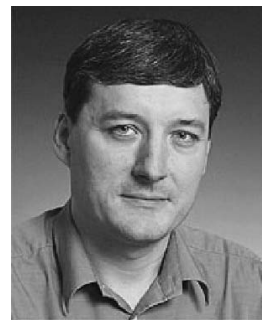

Henning Skriver received the M.Sc. and Ph.D. degrees in electrical engineering from the Technical University of Denmark, Lyngby, Denmark, in 1983 and 1989, respectively.

Since 1983, he has been with the Technical University of Denmark (DTU), where he is currently an Associate Professor and Head of Department with the Department of Microwaves and Remote Sensing, National Space Institute, DTU Space. His work has primarily been concerned with various topics related to the utilization of synthetic aperture radar (SAR) data for different applications. His work has covered different applications, such as sea ice parameter retrieval from SAR data, and different aspects of land applications of SAR data, such as forestry, agricultural, environmental, and topographic mapping applications using both satellite SAR data and data from polarimetric SAR's, such as the Danish airborne polarimetric SAR, EMISAR, and the German experimental SAR. His interests also include various methods for processing of SAR data, such as SAR image simulation, SAR image filtering, speckle statistics, texture analysis, segmentation, calibration, change detection, classification, and polarimetric analysis and processing.

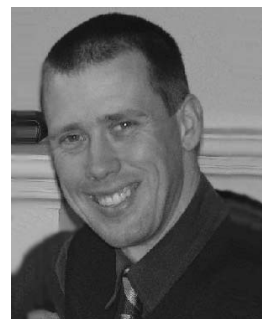

Niko E. C. Verhoest received the Engineering and $\mathrm{Ph} . \mathrm{D}$. degrees in applied biological sciences from Ghent University, Gent, Belgium, in 1994 and 2000, respectively.

He has been Teaching Assistant (1998-2000) and Assistant Professor (2000-2002) with the Laboratory of Hydrology and Water Management, Ghent University. In 2002, he became Associate Professor of hydrology and water management with the Faculty of Bioscience Engineering, Ghent University. His research interests include hydrological applications of radar remote sensing.

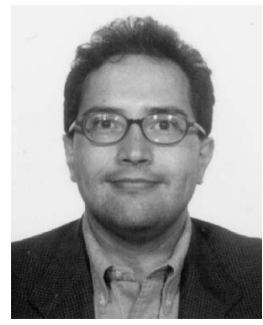

Francesco Mattia (M'99-SM'08) received the Laurea degree in physics and the M.S. degree in signal processing from the University of Bari, Bari, Italy, in 1990 and 1994, respectively, and the Ph.D. degree from the University Paul Sabatier, Toulouse, France, in 1999 .

From 1991 to 1994, he was a grant holder of the Italian National Council of Research (CNR) and the European Commission at the Institute for Remote Sensing Applications of the Joint Research Centre, Ispra, Italy. Since 1995, he has been with CNR where he is currently Senior Research Scientist with the Institute of Intelligent Systems for Automation (ISSIA), CNR, Bari. During 1996-1999, he was a Visiting Scientist with the Centre d'Etudes Spatiales de la Biosphère (CESBIO), Toulouse. In 2007, he was the Coorganizer of the 5th International Symposium on Retrieval of Bio- and Geophysical Parameters from SAR Data for Land Applications, held in Bari. His scientific interests include the direct and inverse modeling of microwave scattering from natural surfaces and the use of information derived from Earth observation sensors to improve land surface process models (e.g., hydrologic or crop growth models). 